\title{
Assembling the puzzle of polymorphism
}

\author{
James M. Hammel, MD
}

From the Department of Cardiothoracic Surgery, Children's Hospital and Medical Center, Omaha, Neb.

Disclosures: Author has nothing to disclose with regard to commercial support.

Received for publication Sept 15, 2017; accepted for publication Sept 16, 2017; available ahead of print Oct 15, 2017.

Address for reprints: James M. Hammel, MD, Cardiothoracic Surgery, Children's Hospital and Medical Center, 8200 Dodge, Omaha, NE 68114 (E-mail: jhammel@chsomaha.org).

J Thorac Cardiovasc Surg 2018;155:1138

$0022-5223 / \$ 36.00$

Copyright $($ c 2017 by The American Association for Thoracic Surgery

https://doi.org/10.1016/j.jtcvs.2017.09.075

Infants with congenital heart disease are not all the same. In addition to the broad range of cardiac anatomic diagnoses and the diversity of medical and surgical approaches to care, previously intangible patient factors mean that some seem to do well and others seem to do less well. Some of these patient factors are now attributable to genetic polymorphisms - traits, some apparent, some not, that are present in a significant fraction of the population. In this issue of the Journal, Kim and colleagues ${ }^{1}$ present the surprising impact of one such polymorphism, deficiency in the production of mannose-binding lectin (MBL), on neurodevelopmental outcome after infant surgery.

MBL is a component of innate immunity. Its understood role is mainly to bind repeated polysaccharide targets on bacteria and other microorganisms, then to activate complement through the lectin pathway. It also plays a role in the removal of injured or apoptotic cells and debris. MLB is particularly important in neonates, whose adaptive immune systems are immature. But this article is about neurodevelopment, not infection.

This work by Kim and colleagues ${ }^{1}$ extends the striking findings reported by Gaynor and colleagues ${ }^{2}$ regarding the neurodevelopmental consequences of polymorphism of apolipoprotein E. Unlike apolipoprotein E, however, which has a mechanistically apparent role in central nervous system recovery from stresses and injuries, the function of MBL in the brain and the mechanism through which its deficiency contributes to poorer neurologic outcome are not clear. As Kim and colleagues ${ }^{1}$ point out, in various models, the effects of deficiency of MBL on the brain are mixed. Furthermore, this study reports shorter preoperative and postoperative stays in the MBL-deficient group, suggesting a positive effect that perhaps has to do with MBL's harmful role in ischemia and reperfusion. Given the confusion, it becomes all the more critical that this research has been conducted and reported with such care. To detect a signal of neurodevelopmental effect amid the noise of complexity of a diverse population of neonates and infants undergoing a variety of operations, Kim and colleagues ${ }^{1}$ have carefully executed their statistical analysis in a way that the reader is likely to find highly credible. Their work supports the

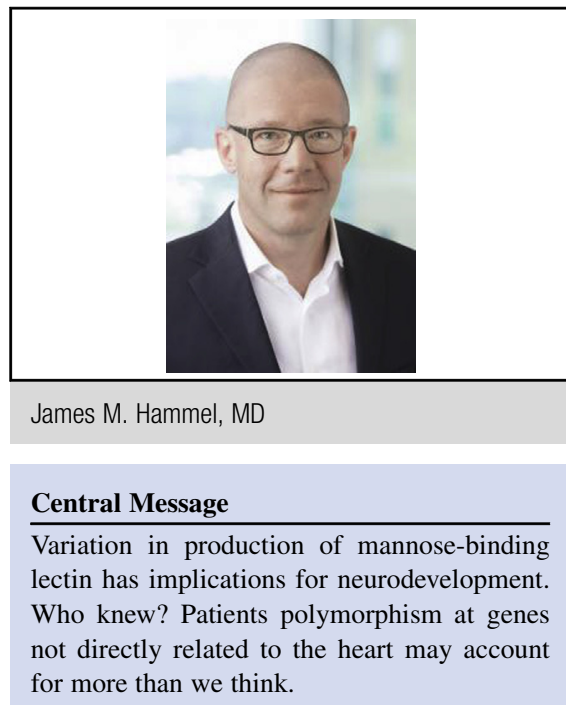

See Article page 1139 .

earlier hypothesis advanced by Yager and associates ${ }^{3}$ that MBL acts through an as-yet unknown mechanism to protect the brain in certain situations.

This work of Kim and colleagues ${ }^{1}$ explains a further fraction of how and why infants vary in their responses to intervention. How can we put this knowledge to use? Recombinant MBL is available experimentally, as are MBL blockers - if only we could figure out whether on balance we wanted more MBL or less. MBL level has been shown to be lower in preterm than in term neonates, whether they have the genetically deficient or the wild-type MBL genotype, and the level rises during the first weeks after birth in those with the wild-type haplotype. ${ }^{4}$ Perhaps this is another reason to delay surgery when feasible. The MBL effect is not likely to move that argument much. By putting together more of the puzzle of patient polymorphism, however, this work helps us to understand our patients more completely.

\section{References}

1. Kim DS, Li YK, Kim JH, Berquist C, Gerdes M, Bernbaum JC, et al. Autosomal dominant mannose-binding lectin (MBL) deficiency is associated with worse neurodevelopmental outcomes after cardiac surgery in infants. $J$ Thorac Cardiovasc Surg. 2018;155:1139-47.

2. Gaynor JW, Nord AS, Wernovsky G, Bernbaum J, Solot CB, Burnham N, et al. Apolipoprotein E genotype modifies the risk of behavior problems after infant cardiac surgery. Pediatrics. 2009;124:241-50.

3. Yager PH, You Z, Qin T, Kim HH, Takahashi K, Ezekowitz AB, et al. Mannose binding lectin gene deficiency increases susceptibility to traumatic brain injury in mice. J Cereb Blood Flow Metab. 2008;28:1030-9.

4. Frakking FN, Brouwer N, Zweers D, Merkus MP, Kuijpers TW, Offringa M, et al. High prevalence of mannose-binding lectin (MBL) deficiency in premature neonates. Clin Exp Immunol. 2006;145:5-12. 